\title{
Impact of age on harm risks of female genital mutilation: analysis of demographic and health
}

\section{surveys}

\begin{abstract}
This paper investigates the problem of Female Genital Mutilation (FGM), also known as 'Female Genital Cutting' or 'female circumcision'. Evidence in this paper is based on 'Demographic \& Health Surveys', carried out in numerous countries. It explores four of the medical problems caused by Female Genital Mutilation: excessive bleeding; infection; urination problems; and swelling. This paper focuses on the age at which the circumcision took place, and the Type of FGM. This paper confirms previous evidence that FGM is harmful. For FGM Types I and II (clitoridectomy and excision) and IV (other), victims are more vulnerable to these four problems if they are older when circumcised; whereas for FGM Type III (infibulation), victims are more at risk if they undergo FGM at a younger age. Investigations into medical responses to FGM problems are reported.
\end{abstract}

Keywords: female genital mutilation, excessive bleeding, infection, urination problems, swelling, Africa
Volume 7 Issue I - 2018

\begin{abstract}
John Simister
Economics, Department of Policy \& International Business, Manchester Metropolitan University, UK

Correspondence: John Simister, Economics, Department of Policy \& International Business, Manchester Metropolitan University, MI5 6BH, UK, Tel 016I-247-3899, Email j.g.simister@mmu.ac.uk
\end{abstract}

Received: January 23, 2018 | Published: February 15, 2018

\section{Introduction}

This paper analyses Female Genital Mutilation (FGM), a traditional practice in many cultures in Africa (and countries with an African diaspora). FGM "is widely recognised as a violation of the human rights of girls and women". ${ }^{1}$ This paper follows mainstream academia: considering FGM as a type of violence against females with harmful effects in both the short and long term. ${ }^{2}$ Many researchers reported serious medical problems caused by FGM. ${ }^{1}$ FGM is often viewed as a way women are controlled, benefitting men. ${ }^{1}$ However, FGM is sometimes seen as a way an African person can assert their ethnic identity. ${ }^{3}$ Perhaps all readers can agree on the need for more information: Shell-Duncan et al. ${ }^{2}$ wrote "silence on the topic no longer seems to be an option, and the choice that remains is between informed and noninformed discussion". This paper investigates how the risk of experiencing FGM varies, using data from household surveys in eleven countries. In particular, it focuses on age at which FGM occurs as a key factor in understanding harmful effects of FGM. It would be desirable for more women with personal experience of FGM to write on this subject. "Most studies on female genital cutting (FGC) in Africa have been conducted by "outsiders," individuals who are not from the societies they analyze and who have no personal experience of any form of the operation [...] "insider" voices from initiated/"circumcised" African women scholars can go a long way toward providing fresh approaches to our understanding of these practices and their continued significance to most African women". ${ }^{4}$ More research on FGM is needed: this could be carried out by victims, or non-victims, or - preferably - both.

\section{Literature review}

FGM is a controversial subject: for example, some writers prefer not to use the word "mutilation". Yoder et al., 5 referred to the World Health Organization's view: "In the mid-1990s, WHO and many other groups adopted the term female genital mutilation (FGM) to describe the cutting of female genitalia, for it emphasizes the permanent physical damage done to the body. This is the term used by the majority of English speakers, as well as many activists who direct interventions against the practice, but there seems to be a clear shift toward using FGC". Some writers prefer the term FGM/C; others choose the term 'female circumcision'. There is widespread agreement that FGM is harmful - unlike male circumcision, which is relatively harmless or even beneficial. ${ }^{6,7}$ Kaplan et al., ${ }^{8}$ stated that all types of FGM have consequences which undermine the health and well-being of newborns, girls, and women. Harmful effects include shock, haemorrhage, and infections; (and in the longer term) pain, infections, keloids, fibrosis, infertility, complications in childbirth, and psychological problems. Earlier research on FGM was "dominated by personal accounts of tragic events, small scale studies of circumcision in a town or a set of villages, and studies of medical complications of circumcised women delivering in a hospital"; 5 in recent years, there is increasing use of clinical methods to study FGM-Obermeyer ${ }^{9}$ provides an overview.

In many parts of Africa, men traditionally migrated long distances for their cattle to reach pastures ${ }^{10}$ women and children often remained at home, sometimes for weeks or months - a lifestyle known as 'transhumance'. Some writers appear to imply FGM is related to nomadic pastoralism in north/central Africa: for example, "there is a major problem of the low status of women in pastoral societies, characterised by low levels of access to health and education as well as often forced marriage at tender age, lack of inheritance rights, isolation from the decision-making processes, restriction largely to owning small ruminants and the practice of female genital mutilation in some communities". ${ }^{11}$ Perhaps FGM has been designed by men, to discourage their wives from having sex with other men; whether or not this could explain the origins of FGM, it is out-of-place in contemporary Africa. This speculation seems impossible to test; and doesn't explain why women would accept it for their daughters. Nevertheless, there is widespread agreement that FGM reduces female promiscuity. Rawat ${ }^{1}$ wrote "FGM is deeply rooted in gender 
inequality and attempts to control women's sexuality". Finke ${ }^{12}$ claims FGM is partly imposed because female sexuality must be controlled, according to people who impose FGM. To be more specific, "The most radical form of female "circumcision" is known as infibulation, or pharaonic circumcision. The former term is Latin and is thought to refer to the ancient Roman practice of fastening a fibula, or clasp, through the labia majora to prevent women from having extramarital sex". ${ }^{2}$ In general, all forms of female genital cutting are alleged to be potentially associated with diminished sexual pleasure and, in certain cases, inability to experience a clitoral orgasm. Infibulated women may experience painful intercourse and often have to be cut open for penetration to occur at all". ${ }^{2}$

$\mathrm{UNICEF}^{13}$ reports that FGM is most frequently practiced in Africa \& the Middle East; adjacent countries often have similar FGM prevalence rates - for example, Eritrea, Ethiopia \& Sudan all have high prevalence, whereas FGM risk is much lower in Kenya \& Tanzania. A country may seem to depart from the regional pattern: for example, FGM prevalence is lower in Niger than in countries around Niger, ${ }^{13}$ but national boundaries have limited influence. The distribution of FGM is best understood by ethnicity, and ethnic groups practicing FGM often straddle national boundaries. "Those close together geographically do not necessarily share the practice; for example, in Kenya the Kikuyu historically practiced excision, whereas the Luo did not; in Gambia the Wolof did not practice any form of female genital cutting, whereas most other ethnic groups did". ${ }^{2}$ Coyne et al., ${ }^{2}$ wrote "a key function of FGM is establishing and strengthening individual and group identity"; and "ethnic identity is the most important determinant of the continuation of FGM". In some African countries, FGM seems almost universal: for example, 99\% of women in Guinea (interviewed in 1999) said they had experienced FGM. ${ }^{13}$ In a second group of countries, Costello et al., ${ }^{14}$ described the FGM risk as 'intermediate' ( $25 \%$ to $79 \%$ ): at least some variation in FGM risk in those countries is explained by ethnicity - "Only certain ethnic groups within these countries practice $\mathrm{FGM} / \mathrm{C}$, with intensities varying according to ethnicity and tribal practices". And "In a third group, prevalence rates are between $1 \%$ and $24 \%$. These are countries where only some ethnic groups practice FGM/C". ${ }^{14}$

Religion is often considered a cause of FGM. Costello et al., ${ }^{14}$ found infibulation (FGM type III) is mostly practiced in Islamic countries in Africa-including North Sudan, Somalia, Djibouti, Eritrea, Egypt, and Mali; this might explain why FGM is associated with Islam. However, FGM predates Islam; FGM is practiced by members of other religions including Christianity (in many countries); and many Islamic scholars state that FGM is not a requirement for Islam. ${ }^{14}$ If FGM were caused by Islam, this would lead us to predict the northern part of Nigeria would have high FGM prevalence, because of the (mainly Muslim) Hausa in northern Nigeria; compared with other ethnic groups such as (mainly Christian or Animist) Yoruba and Igbo in southern Nigeria. But this prediction is not supported by evidence: FGM prevalence does vary within Nigeria, but FGM prevalence is almost $60 \%$ in southern Nigeria, compared to $2 \%$ or less in northern Nigeria. ${ }^{13}$ This tendency for Muslims in northern Nigeria to have lower FGM prevalence than non-Muslims in southern Nigeria is clear in the 2013 DHS survey; ${ }^{15}$ northern Nigeria is similar to Niger perhaps because most people in Niger and northern Nigeria are in the Hausa ethnic group. Simister ${ }^{16}$ provided some evidence that FGM is associated with ethnicity, rather than religion; but it is difficult to separate religion from ethnic identity.
Several academics report FGM is becoming 'medicalised': carried out by medical personnel. ${ }^{8}$ Orubuloye et al., ${ }^{9}$ wrote "Nurses are less influenced by their training to be against female "circumcision" than are doctors, and many rely on it for an important part of their income". Medicalization of FGM appears incompatible with the Hippocratic Oath taken by many medical staff, ${ }^{17}$ and has been condemned by WHO "because it creates a sense of legitimacy, gives the erroneous impression that the practice is harmless, and represents a break in medical professionalism and ethical responsibility". ${ }^{8}$ However, surgical interventions such as FGM can be dangerous, if carried out by people without medical training; and making FGM illegal (to protect girls \& women from harm) might have unintended effects ShellDuncan et al., ${ }^{2}$ wrote "victims of botched infibulations may simply be allowed to bleed to death rather than receive medical care when parents, circumcisers, and community members fear prosecution".

Education is relevant to FGM: "Daughters of women with more than a secondary education are less likely than daughters of women at lower levels of education to have been circumcised". ${ }^{15}$ A greater level of education is generally correlated with lower FGM prevalence; ${ }^{1}$ "daughters of mothers who are more highly educated are less likely to have undergone FGM/C than daughters of mothers with little or no education [...] women's education may contribute to a reduction of the practice, but alone it is not sufficient to lead to its abandonment". ${ }^{13}$ Simister ${ }^{16}$ found FGM risk is reduced if a respondent's mother is more educated. Many factors are relevant to the risk of FGM occurring; only a few of them are investigated in empirical analysis in this paper. The remainder of this paper focuses on medical evidence from household surveys on FGM: it considers four types of 'harm' caused by FGM, and distinguishes between different types of FGM.

\section{Methods}

The most reliable FGM data sources are 'Demographic and Health Surveys' (DHS), and 'Multiple Indicator Cluster Surveys' (MICS); ${ }^{16}$ this paper uses DHS data. DHS use very large samples - which allow researchers to study patterns within, and between, countries. ${ }^{18}$ DHS are nationally-representative surveys, including respondents in urban and rural areas. DHS surveys have been carried out in many countries; and can show changes over time. DHS surveys are mainly paid for by the US government (USAID), in co-operation with the government of each country surveyed. DHS questionnaires vary to some extent, from one country to another, and over time; the questionnaire is translated into local languages, which may reduce comparability of findings between countries. Most DHS respondents are females, but a relatively small sample of men is interviewed in most countries where DHS surveys are carried out; for this paper, the sample is limited to female respondents. Female respondents were generally between 15 and 49years of age at the time of interview. DHS interviewers are usually women, who are carefully trained interviewers. DHS tend to ask questions about FGM only in countries where there seems to be a significant problem of FGM (where expected FGM prevalence was $1 \%$ or higher). Survey details vary: the earlier DHS interviews asking about FGM focused on a respondent's experience of FGM, but later DHS surveys focus at least as much on FGM experienced by the respondent's daughter(s). For this paper, data on the respondent's daughter(s) are analysed - except for Figure 1, which also uses respondent's own FGM experience. It is likely that some DHS respondents prefer not to discuss FGM, because it is illegal in many countries (Shell-Duncan, 2016), or embarrassing; this may reduce reported prevalence rates. 
Published analysis on FGM usually distinguishes between four types of FGM: Type I (Clitoridectomy: removing the clitoris); Type II (Excision: removing the clitoris and the labia minora); Type III (Infibulation: narrowing the vaginal opening); and Type IV (other harm to female genitalia, such as incision). ${ }^{1}$ FGM Type is reported by some DHS surveys; but many interviewees found it difficult to categorize FGM into these four types - for example, National Population Commission \& ICF International" ${ }^{15}$ wrote "Questions directed at determining the type of female circumcision were asked of women who reported they had been circumcised [but] the type of circumcision could not be determined for half of the women". In DHS surveys from 2002 to 2010, women were asked three questions "to obtain an approximation of what was done. Women were asked if they were just nicked. If the answer was no, then they were asked if flesh was cut away and/or if the vaginal area was nearly sewn shut". ${ }^{18}$ For this paper, FGM is reduced from four categories to three: infibulation (Type III); if flesh was removed (combining Types I and II); and 'other' (Type IV). Type III remains a separate category: "the most severe type of FGC - infibulation - inflicts greater harm on the physical wellbeing of girls and women than any other type". ${ }^{18}$ It also allows earlier DHS surveys (in Egypt and Chad, which report FGM Type) to be combined with later DHS surveys (which report infibulation and flesh removed, but not FGM Type). Combining Types I and II is not a criticism of the widely-used classification, but a response by the author to data availability.
This paper uses DHS data from most, but not all, countries where responses from individual people are reported. For a few DHS surveys, FGM prevalence data are restricted (at the request of the government of those countries). For some countries, FGM data are reported in $\mathrm{DHS}^{19}$ but not made public. FGM prevalence rates in this paper sometimes differ from DHS, ${ }^{20}$ because DHS 'Gender Indicator Data' reports latest-available data; or because this paper calculates an average for each survey analysed by the author, in that country. Up-to-date FGM prevalence rates are in DHS ${ }^{18}$ and Yoder et al., ${ }^{18}$ For this paper, the author analysed 57 DHS surveys which include FGM; but DHS ${ }^{19}$ reports that 76 of their surveys include FGM. This paper investigates four types of 'harm' (excessive bleeding, infection, urination problems, and swelling), which are included in many DHS surveys. A few DHS surveys add other types of harm, such as 'shock' in DHS Egypt 1995; but the sample-sizes would be much reduced, if more than these four types of harm was studied. Recent DHS surveys do not include the four 'harms' analysed in this paper; hence, DHS surveys analysed here include most - but perhaps not all - relevant DHS surveys available to date. Data for all FGM DHS data analysed by the author are combined into one file, for this paper; hence, (national) weights are not used. Sample-sizes in Table 1 should be regarded as an upper limit (of the number of women who chose to discuss FGM in the DHS surveys). For example, some interviewees had no daughter; hence, they were not asked if their daughter(s) had undergone FGM.

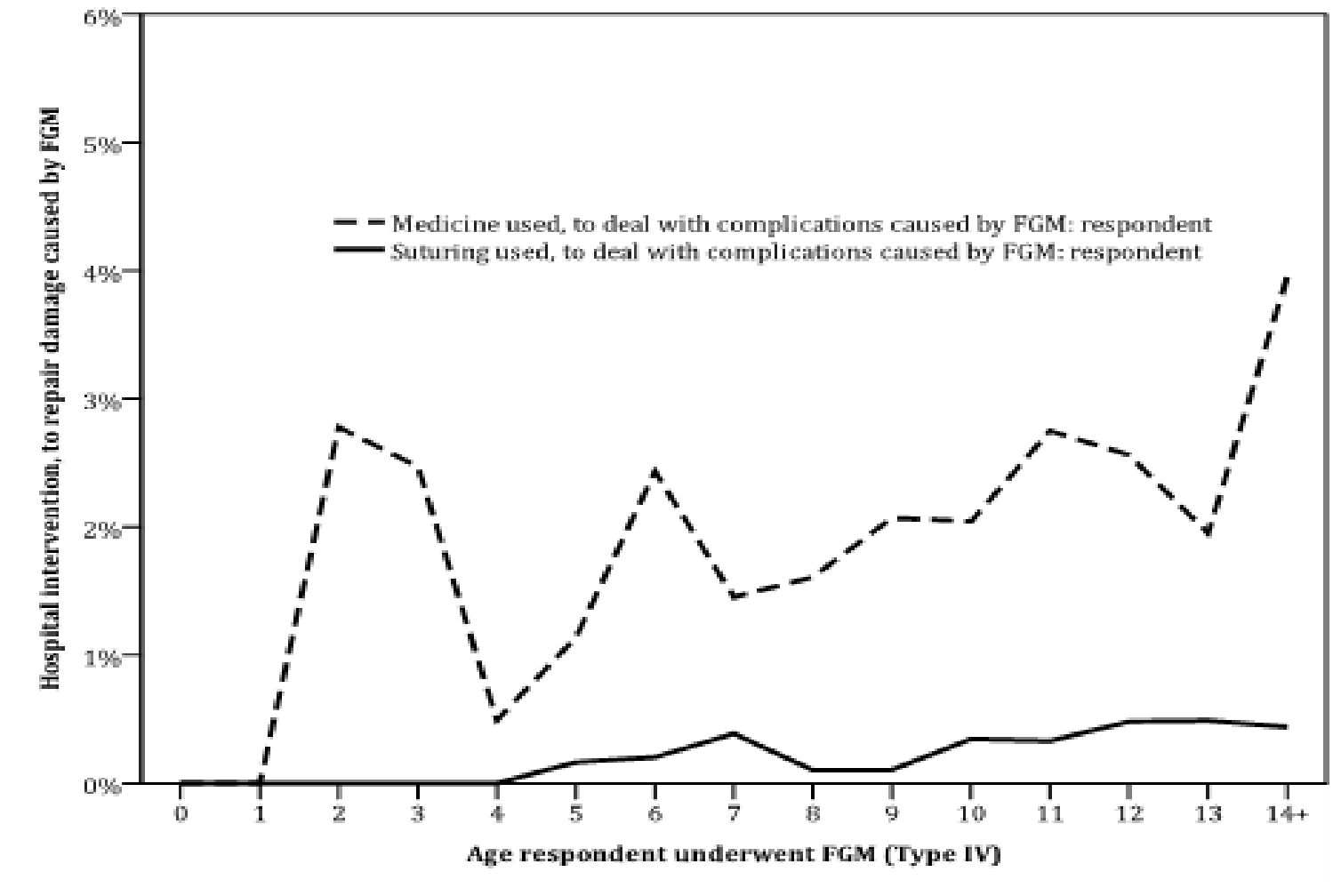

Source: DHS Egypt 1995 survey (analysed by the author).

Figure I Intervention in hospitals, in response to harm caused by FGM: respondents. 
Table I Sample-sizes of surveys analysed for this paper, by country(survey year in brackets)

\begin{tabular}{|c|c|c|c|c|c|}
\hline Country & $\begin{array}{l}\text { Earliest survey } \\
\text { analysed }\end{array}$ & $\begin{array}{l}\text { Next survey } \\
\text { analysed }\end{array}$ & Next survey analysed & Next survey analysed & Next survey analysed \\
\hline Benin & $6,214(2001)$ & $11,877(2006)$ & $11,212(2011)$ & & \\
\hline Burkina Faso & $5,607(1998)$ & $12,049(2003)$ & $17,031(2010)$ & & \\
\hline Cameroon & $1,662(2004)$ & & & & \\
\hline $\begin{array}{l}\text { Central African } \\
\text { Republic }\end{array}$ & $5,884(1994)$ & & & & \\
\hline Chad & $5,407(2004)$ & & & & \\
\hline Cote D'Ivoire & $2,884(1998)$ & $5,165(2005)$ & $9,441(2011)$ & & \\
\hline Egypt & $14,768(1995)$ & $15,572(2000)$ & $9,142(2003)$ & $19,465(2005)$ & $16,523(2008)$ \\
\hline Ethiopia & $15,367(2000)$ & $13,628(2005)$ & & & \\
\hline Ghana & $5,681(2003)$ & & & & \\
\hline Guinea & $6,746(1999)$ & $7,944(2005)$ & $9,130(2012)$ & & \\
\hline Guyana & $1,867(2005)$ & & & & \\
\hline Kenya & $7,873(1998)$ & $8,174(2003)$ & $8,038(2008)$ & & \\
\hline Malawi & $2,683(1996)$ & & & & \\
\hline Mali & $9,704(1995)$ & $12,440(2001)$ & $13,251(2006)$ & $10,240(2012)$ & \\
\hline Niger & $2,424(1995)$ & $3,803(2006)$ & $4,993(2012)$ & & \\
\hline Nigeria & 7,045(1999) & $7,321(2003)$ & $18,487(2008)$ & $24,473(2013)$ & \\
\hline Senegal & $13,732(2005)$ & $14,228(2010)$ & & & \\
\hline Sierra Leone & $7,279(2008)$ & $16,614(2013)$ & & & \\
\hline Sudan & $5,858(1989)$ & & & & \\
\hline Swaziland & $4,981(2006)$ & & & & \\
\hline Tanzania & $8,073(1996)$ & $7,866(2004)$ & $8,504(2010)$ & & \\
\hline Uganda & $2,809(2006)$ & $4,918(2011)$ & & & \\
\hline Yemen & $3,532(2013)$ & & & & \\
\hline
\end{tabular}

Source: DHS surveys(author's analysis).

\section{Results}

Evidence in this paper begins by reporting FGM prevalence rates, by FGM Type, for DHS surveys analysed by the author which report the four standard 'Types' associated with WHO. Tables 2, Table 3 are not claimed to report all relevant DHS surveys (see Methods section), but do include all DHS surveys with these four FGM Types, which have been analysed by the author. Tables $2 \&$ Table 3 provide many insights into FGM prevalence; more details are available in the report for each survey, on the DHS website. In this context, the key point is that (impressive as these DHS surveys are), relatively few DHS surveys tell us about these four FGM Types. Instead, we should consider Table 4: it provides slightly less detail (one less column than Tables $2 \& 3$ ), but many more rows. Table 4 is confusing, because each row doesn't add up to $100 \%$ (as rows in Tables $2 \&$ Table 3 do). In general, each country exhibits more than $100 \%$ on each row: many respondents experienced more than one of the three FGM categories. This produces problems: for this paper, it suggests we cannot compare the (relatively few) countries in Tables $2 \&$ Table 3, with the (larger number of) countries in Table 4. It also suggests a more fundamental problem: can we rely on the WHO classification of FGM into Types I II III and IV? This paper does not attempt to resolve such problems; researchers are aware that the WHO system is imperfect; but it remains a useful way to make sense of a complicated issue. The remainder of this paper interprets DHS survey data on 'Flesh removed from genital area' as FGM Type I or II; 'Genital area sown closed' as FGM Type III; and 'Genital area just nicked, or pinched without removal' as FGM Type IV. If a respondent reports infibulation and flesh removal, this is categorized by the author as infibulation. Improving classification may be helpful, but reducing FGM prevalence seems more urgent than trying to improve a definition which is widely accepted. 
Analysis of DHS surveys now turns to the age at which FGM took place, in Figure 2. Some respondents referred to 'infancy', rather than an age in years; the author interpreted this answer as 1 year old, but FGM is sometimes carried out on babies' age less than 12 months. DHS report four types of harm from FGM (shown in Figure 2), but there are many more harmful effects of FGM. ${ }^{21}$ It may be unrealistic for a questionnaire-based survey such as DHS to include all possible hardships which FGM is thought to impose; qualitative research may shed more light on such intimate details. Figure 2 shows the experience of these four types of harm, caused by FGM Type I or II (clitoridectomy or excision), among daughters of DHS respondents; it only includes women who have undergone FGM. Our interpretation of Figure 2 is made more difficult by language issues - the precise meaning of words in each language is likely to differ from the base questionnaire (written in English). The terms such as 'excessive bleeding' were interpreted by interviewees, most of whom are not medically trained. Perhaps we could interpret 'excessive bleeding' and 'infection/improper healing' as short-term responses to the FGM; whereas swelling (of the genital area), and problems with urination, might be more long-term issues.

Finke $^{12}$ explains the mind-set of people who order, or carry out, FGM on children: "The rite of excision is not considered damaging to health: subsequent health problems are attributed to other causes. It is the will of the gods". However, harm from FGM appears to be systematic, rather than random: Figure 2 shows an upward trend, as we look from left (youngest children) to right (oldest children, or occasionally adults). This trend implies higher risks, if FGM is used on older children. Figure 3 shows the experience of four types of harm, resulting from FGM Type III (infibulation), for the daughter of the respondent. Unlike Figure 2, we can see in Figure 3 a downtrend for these risks, as we go from left to right; this suggests that children are more vulnerable to these harmful side-effects of FGM, if it is carried out when children are younger. The pattern is not entirely clear - perhaps risks increase again on the right-hand-side of Figure 3 , if FGM occurs when the person is aged over 13 years of age: more research may be able to clarify this. Figure 4 shows the risk of harm, while Type IV FGM is being carried out. In Figure 4, we see a tendency for risk (of the four types of harm included in most DHS surveys) to increase, as we go from left (younger) to right (older). This is similar to Figure 2 (for FGM Types I/II), but the opposite trend to Figure 3 (for FGM Type III). Reasons for apparent inconsistencies are not clear: more research is needed. Meanwhile, the following evidence may be a useful guide; but should be considered tentative, because they are based on just one DHS survey. The DHS approach to data collection is enhanced for social scientists, by using a standardized approach; but in some surveys, DHS push the boundaries of knowledge even further, by adding innovative questions. In the case of Egypt in 1995, the DHS survey asked if there were complications during the FGM procedures which led to hospitalization - and, if so, what medical procedures were carried out to limit the damage. Figures $1 \&$ Figure 5 report evidence on two interventions by hospital staff: medicine/injections and suturing (the survey also included blood transfusions, but there were too few cases to provide reliable evidence).

This 1975 Egyptian sample is limited to women interviewees (Figure 1), and their daughters (Figure 5), who had experienced Type IV FGM - very few women in this sample had experienced Types I, II, or III FGM. Hence, Figures $1 \& 5$ could be compared with Figure 4. Figure 1 shows a tendency for intervention in hospitals (after unsuccessful FGM) to increase, as we go from left to right. Presumably these children (and a few adults) were only taken to hospital if the FGM went dangerously wrong: every FGM victim would be expected to experience pain. Figure 1 suggests there was a bigger problem when FGM Type IV was carried out among older children, rather than younger children (consistent with Figure 4). DHS do not report the type of medicines used, simply referring to 'medicine/injection'; we cannot tell if this medication is a response to infection. Similarly, suturing by hospitals could indicate that the person carrying out FGM made cuts requiring stitches - but this is speculation. We see much more use of medicine than suturing in Figure 1; this may seem surprising, because there is more 'excessive bleeding' than 'infection/ improper healing' in Figure 4. Figure 5 is similar to Figure 1, but for Figure 5 refers to daughter(s) of respondents; whereas Figure 1 relates to the experience of a respondent herself. In Figure 5, we see the same upward trend as Figure 1: older children tend to be more vulnerable than younger children. It is unreliable to put too much trust in one survey: scientific method suggests we should seek replication. It can be argued that Figures 2, Figure 4-5 in this paper imply a girl has more risk of harm if FGM is imposed when she is older; but Figure 3 (for FGM Type III) casts doubt on this hypothesis. This paper offers no explanation of why infibulation seems so different to other forms of FGM.

Table 5 shows evidence from the DHS Guinea survey in 1999, to illustrate possible links between harms from FGM, and Type of FGM carried out (using all four FGM Types - later DHS surveys do not ask respondents which Type applies to herself). In Table 5, the risk of 'excessive bleeding' is higher for FGM type III (infibulation), than for the other three types of FGM. Table 5 is based on one survey; numbers in brackets show sample-sizes are relatively small, so Table 5 should be interpreted with care. Table 6 reports regression results, using DHS data from Burkina Faso, Benin, Cameroon, Egypt, Guinea, Mali, Niger, Nigeria, Senegal, and Chad. DHS report whether or not flesh was removed from her genital area, which the author interprets as FGM Type I/II; infibulation, Type III; and 'other' FGM (such as a nick), Type IV. Logistic regression is used, because the dependent variable is zero or one; logistic regression has been used in previous FGM research, such as Larsen et al. ${ }^{22}$ The first regression shows 'excessive bleeding': a daughter who had 'excessive' bleeding after FGM was coded as 1; or coded zero, if her bleeding was not considered excessive by the respondent. The Nagelkerke $\mathrm{R}^{2}$ value estimates how much of the dependent variable is explained by explanatory variables: age of circumcision; and who carried out the FGM.

In Table 6, the three columns labelled 'Circumcised by' (doctor; other health professional; or traditional birth attendant) are each relative to the 'reference' category: traditional circumcisers. If these categories were zero, then they would be no better or worse than traditional circumcisers at carrying out the process, regarding these four types of harm. It is unsurprising that coefficients for trained medical staff (doctors; and other health professionals) are always negative - and asterisks show that differences between doctors \& traditional circumcisers are statistically significant ('swelling' is not statistically significant). It may seem surprising that 'traditional birth attendants' (TBA) are also better than traditional circumcisers (perhaps a TBA usually has more medical education than a circumciser). These regression results generally confirm the slopes of lines in the first three Figures of this paper: the 'Age when circumcised' coefficients (on the left of Table 6) tend to be positive for FGM Type I/II, and Type IV (corresponding to upward slopes in Figures 2 \& Figure 4); but tend to be negative for FGM Type III (corresponding to downward 
slopes in Figure 3). However, expected pattern do not always apply: the age coefficient for 'infection' in FGM Type I/II is negative (-0.13), and statistically significant - this result is unreliable, due to smaller samples for FGM Type III than for Type I/II. Table 7 investigates the indication, in Table 6 , that traditional circumcision practitioners are less effective at carrying out FGM than other people. Table 7 shows the fraction of respondents' daughters who experienced these four types of harm; the bottom row shows the largest risks, confirming that traditional circumcisers are the least appropriate people to carry out the role. Note, however, that this does not justify trained medical staff from carrying out FGM: the process has harmful long-term effects, even if it can be carried out without mistakes which lead to the victim being hospitalized.

Table 2 Type of FGM carried out on respondent, by country

\begin{tabular}{llllll}
\hline & Type I: Clitoridectomy & Type II: Excision & Type III: Infibulation & Type IV: Other & Total \\
\hline Burkina Faso & $32 \%$ & $68 \%$ & $1 \%$ & $0 \%$ & $100 \%$ \\
Cote D'Ivoire & $75 \%$ & $25 \%$ & & & $100 \%$ \\
Guinea & $45 \%$ & $47 \%$ & $6 \%$ & $2 \%$ & $100 \%$ \\
Mali & $53 \%$ & $46 \%$ & $0.40 \%$ & & $100 \%$ \\
Niger & $91 \%$ & $5 \%$ & $4 \%$ & $22 \%$ & $100 \%$ \\
Nigeria & $71 \%$ & $1 \%$ & $6 \%$ & $0 \%$ & $100 \%$ \\
Sudan & $15 \%$ & $3 \%$ & $82 \%$ & $0 \%$ & $100 \%$ \\
Tanzania & $60 \%$ & $35 \%$ & $5 \%$ & $100 \%$ \\
\hline
\end{tabular}

Source: DHS surveys(author's analysis)

Table 3 Type of FGM carried out on respondent's daughter, by country

\begin{tabular}{llllll}
\hline & Type I: Clitoridectomy & Type II: Excision & Type III: Infibulation & Type IV: Other & Total \\
\hline Burkina Faso & $33 \%$ & $67 \%$ & $1 \%$ & & $100 \%$ \\
Cote D'Ivoire & $100 \%$ & & & $5 \%$ & $100 \%$ \\
Guinea & $55 \%$ & $35 \%$ & $5 \%$ & $100 \%$ \\
Kenya & $95 \%$ & $4 \%$ & $0.20 \%$ & $100 \%$ \\
Niger & $89 \%$ & $11 \%$ & & $100 \%$ \\
\hline
\end{tabular}

Source: DHS surveys(author's analysis).

Table 4 FGM carried out on respondent's daughter, by country

\begin{tabular}{|c|c|c|c|}
\hline Country & $\begin{array}{l}\text { Flesh removed from genital area(FGM } \\
\text { Type I / II) }\end{array}$ & $\begin{array}{l}\text { Genital area sown closed: infibulation(FGM Type } \\
\text { III) }\end{array}$ & $\begin{array}{l}\text { Genital area } \\
\text { just nicked, or } \\
\text { 'pinched without } \\
\text { removal'(FGM Type } \\
\text { IV) }\end{array}$ \\
\hline Burkina Faso & $89 \%$ & $1 \%$ & $86 \%$ \\
\hline Benin & $94 \%$ & $6 \%$ & $64 \%$ \\
\hline Cote D'Ivoire & $94 \%$ & $7 \%$ & $86 \%$ \\
\hline Cameroon & $91 \%$ & $5 \%$ & $80 \%$ \\
\hline Egypt & & $1 \%$ & \\
\hline Ethiopia & $93 \%$ & $16 \%$ & $50 \%$ \\
\hline Guinea & $95 \%$ & $8 \%$ & $76 \%$ \\
\hline Kenya & $97 \%$ & $19 \%$ & $76 \%$ \\
\hline Mali & $89 \%$ & $10 \%$ & $62 \%$ \\
\hline Niger & $85 \%$ & $9 \%$ & $7 \%$ \\
\hline Nigeria & $78 \%$ & $8 \%$ & $31 \%$ \\
\hline Sierra Leone & $93 \%$ & $8 \%$ & $27 \%$ \\
\hline Senegal & $99 \%$ & $13 \%$ & $24 \%$ \\
\hline Chad & $64 \%$ & $7 \%$ & $93 \%$ \\
\hline Togo & $82 \%$ & $20 \%$ & $85 \%$ \\
\hline Tanzania & $97 \%$ & $3 \%$ & $77 \%$ \\
\hline Yemen & $94 \%$ & & \\
\hline
\end{tabular}

Source: DHS surveys(author's analysis). 
Table 5 Problems caused by FGM, by Type of FGM, for daughter(s) of respondent

\begin{tabular}{lllll}
\hline Type of FGM & Excessive bleeding & $\begin{array}{l}\text { Difficulty with } \\
\text { urination or } \\
\text { retention }\end{array}$ & $\begin{array}{l}\text { Problem of swelling in } \\
\text { genital area }\end{array}$ & Problem of infection/ improper healing \\
\hline $\begin{array}{l}\text { Type I: } \\
\text { Clitoridectomy }\end{array}$ & $32 \%(1129$ cases $)$ & $22 \%(1134$ cases $)$ & $6 \%(1130$ cases $)$ & $13 \%(1126$ cases $)$ \\
$\begin{array}{l}\text { Type II: Excision } \\
\text { Type III: }\end{array}$ & $37 \%(763$ cases $)$ & $16 \%(757$ cases $)$ & $4 \%(756$ cases $)$ & $16 \%(753$ cases $)$ \\
$\begin{array}{l}\text { Infibulation } \\
\text { Type IV: Other }\end{array}$ & $11 \%(108$ cases $)$ & $11 \%(109$ cases $)$ & $0 \%(109$ cases $)$ & $10 \%(109$ cases $)$ \\
\hline
\end{tabular}

Source: DHS surveys(author's analysis).

Table 6 Regression analysis on four types of health problems affecting respondent's daughter

\begin{tabular}{|c|c|c|c|c|c|c|c|}
\hline $\begin{array}{l}\text { Dependent } \\
\text { variable }\end{array}$ & $\begin{array}{l}\text { Age FGM } \\
\text { carried out }\end{array}$ & $\begin{array}{l}\text { FGM } \\
\text { carried out } \\
\text { by a doctor }\end{array}$ & $\begin{array}{l}\text { FGM carried } \\
\text { out by } \\
\text { other health } \\
\text { professional }\end{array}$ & $\begin{array}{l}\text { FGM carried out } \\
\text { by 'Matrone' or } \\
\text { traditional birth } \\
\text { attendant }\end{array}$ & Constant & $\begin{array}{l}\text { Nagelkerke R } \\
\text { square }\end{array}$ & $\begin{array}{l}\text { Sample } \\
\text { size }\end{array}$ \\
\hline \multicolumn{8}{|c|}{ FGM Type I or II } \\
\hline $\begin{array}{l}\text { Excessive } \\
\text { bleeding }\end{array}$ & $0.02 * *$ & $-2.02 * *$ & $-1.28 * *$ & $-1.47 * *$ & $-0.35^{* *}$ & $8 \%$ & 18,018 \\
\hline $\begin{array}{l}\text { Urination } \\
\text { problem }\end{array}$ & $0.01 *$ & $-1.14 * *$ & $-0.91 * *$ & $-0.73 * *$ & $-0.83 * *$ & $2 \%$ & 18,146 \\
\hline Swelling & 0.02 & $-1.18 * *$ & $-1.13^{* *}$ & $-1.12 * *$ & $-2.03^{* *}$ & $3 \%$ & 18,116 \\
\hline Infection & $-0.02 * *$ & $-1.16^{* *}$ & $-0.46^{* *}$ & $-0.91 * *$ & $-1.55^{* *}$ & $2 \%$ & 18,089 \\
\hline \multicolumn{8}{|c|}{ FGM Type III } \\
\hline $\begin{array}{l}\text { Excess } \\
\text { bleeding }\end{array}$ & $-0.04 *$ & $-2.04 * *$ & $-2.02 * *$ & $-1.45 * *$ & $0.76^{* *}$ & $5 \%$ & 2,010 \\
\hline $\begin{array}{l}\text { Urination } \\
\text { problem }\end{array}$ & $-0.05 * *$ & $-0.85 * *$ & $-0.76^{*}$ & -0.28 & -0.45 & $2 \%$ & 2,014 \\
\hline Swelling & $-0.06^{*}$ & $-1.21 * *$ & -0.77 & -0.21 & $-1.36^{* *}$ & $2 \%$ & 2,013 \\
\hline Infection & $-0.13^{* *}$ & $-1.51 * *$ & -0.33 & -0.09 & $-0.91 * *$ & $6 \%$ & 2,006 \\
\hline \multicolumn{8}{|c|}{ FGM Type IV } \\
\hline $\begin{array}{l}\text { Excess } \\
\text { bleeding }\end{array}$ & $0.09 * *$ & $-3.80 * *$ & $-3.80 * *$ & $-2.45 * *$ & 0.58 & $38 \%$ & 823 \\
\hline $\begin{array}{l}\text { Urination } \\
\text { problem }\end{array}$ & 0.04 & $-2.52 * *$ & $-2.35^{* *}$ & $-2.19 * *$ & 0.38 & $25 \%$ & 824 \\
\hline Swelling & -0.01 & -0.64 & -18.93 & -0.21 & $-2.21 * *$ & $5 \%$ & 822 \\
\hline Infection & $0.12^{* *}$ & $-1.64 * *$ & $-2.29 * *$ & 0.12 & $-1.99 * *$ & $10 \%$ & 823 \\
\hline
\end{tabular}

Source: DHS surveys(author's analysis).

** indicates a coefficient which is statistically significant at the $1 \%$ level;

*shows significance at the $5 \%$ level. The four types of health problems(reported by DHS) are the ones shown in Figure 2. 
Table 7 Harmful effects from FGM, by person who carried out the process

\begin{tabular}{lllll}
\hline $\begin{array}{l}\text { Person who carried Out FGM on the } \\
\text { respondent's daughter }\end{array}$ & $\begin{array}{l}\text { Excessive } \\
\text { bleeding }\end{array}$ & $\begin{array}{l}\text { Urination/ } \\
\text { retention } \\
\text { problem }\end{array}$ & Problem of swelling & Infection/ improper healing \\
\hline $\begin{array}{l}\text { Doctor } \\
\begin{array}{l}\text { Trained nurse/midwife/other health } \\
\text { professional }\end{array}\end{array}$ & $5 \%$ & $5 \%$ & $1 \%$ & $2 \%$ \\
$\begin{array}{l}\text { Matrone/ daya traditional birth attendant } \\
\text { Circumcision practitioner }\end{array}$ & $15 \%$ & $10 \%$ & $3 \%$ & $6 \%$ \\
\hline
\end{tabular}

Source: DHS surveys(author's analysis).

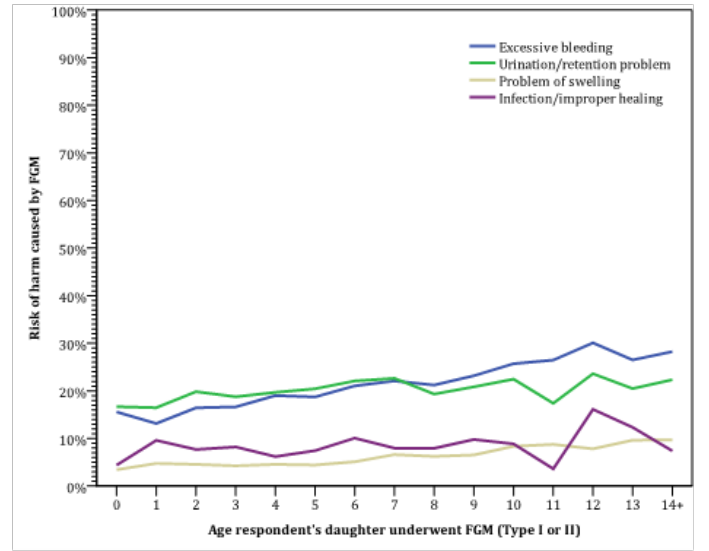

Source: DHS surveys in Benin, Burkina Faso, Cameroon, Chad, Guinea, Mali, Niger, Nigeria, Senegal (author's analysis). Sample sizes are shown in Table 6.

Figure 2 Risk of four types of harm from FGMTypes I/II, by age of respondent's daughter.

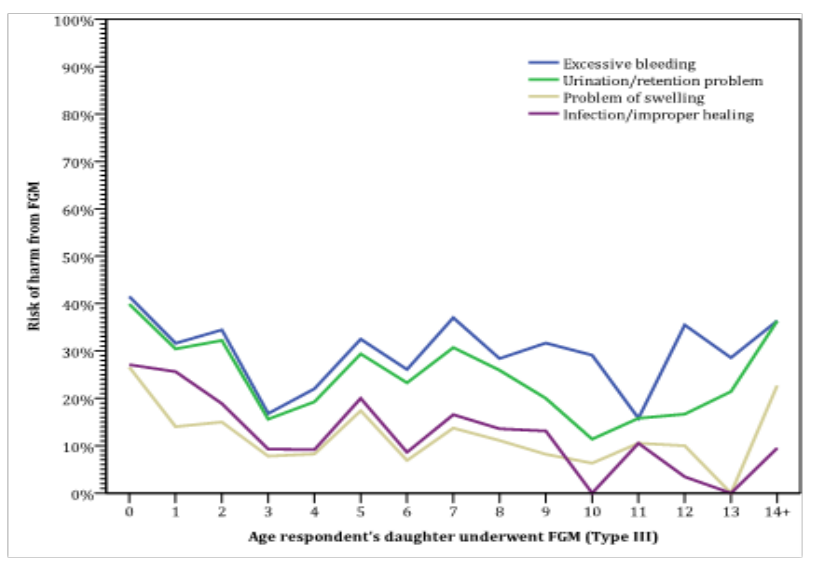

Source: DHS surveys in Benin, Burkina Faso, Chad, Egypt, Guinea, Mali, Niger, Nigeria, Senegal (author's analysis). Sample sizes are shown in Table 6.

Figure 3 Risk of four types of harm from FGM Type III, among respondent's daughters.

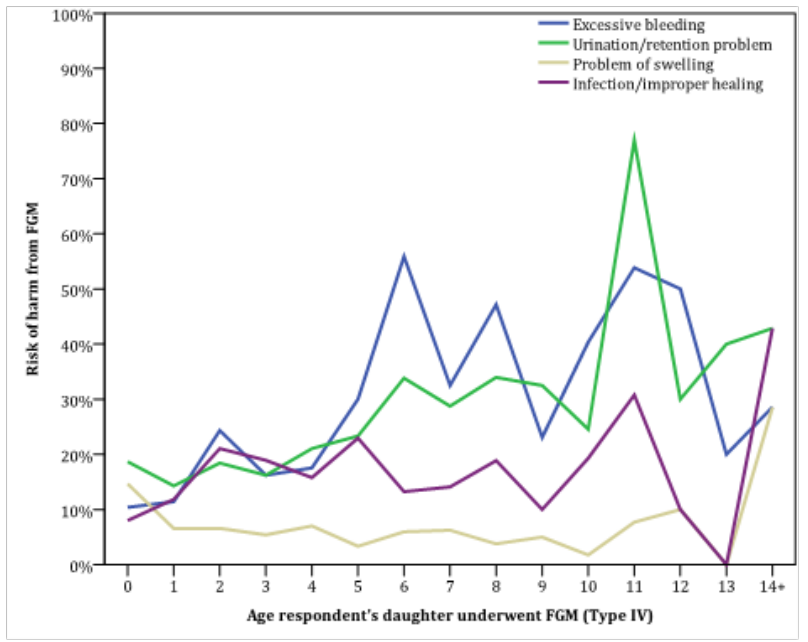

Source: DHS surveys in Benin, Burkina Faso, Cameroon, Chad, Guinea, Mali, Niger, Nigeria, Senegal (author's analysis). Sample sizes are shown in Table 6.

Figure 4 Risk of four types of harm from FGM Type IV, among respondent's daughters.

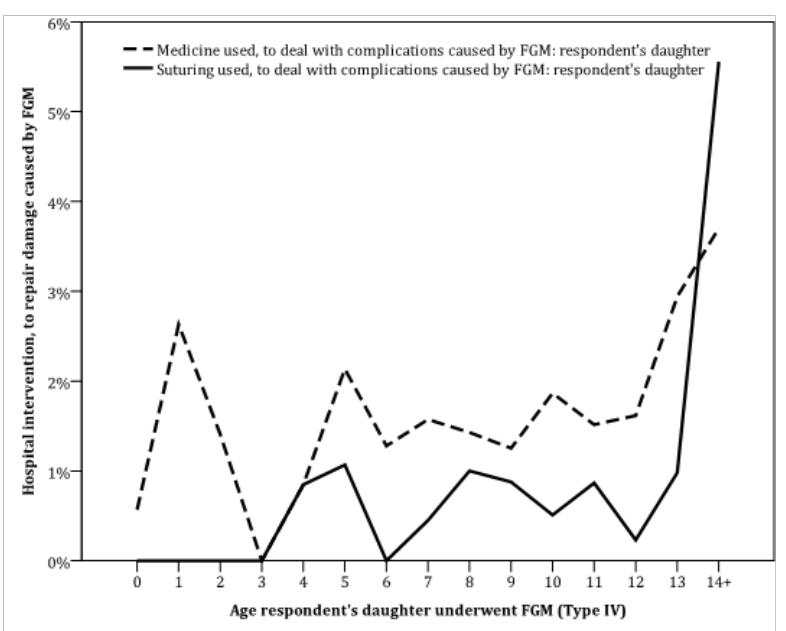

Source: DHS Egypt 1995 survey (analysed by the author).

Figure $\mathbf{5}$ Intervention in hospitals, in response to harm caused by FGM: daughters of respondents. 


\section{Discussion}

DHS surveys provide information on the FGM prevalence rate among female respondents; and among daughters of respondents. The standardization of DHS and MICS questionnaires is very helpful to researchers who study FGM. The provision of these impressive datasets is a tribute to medical professionals who provided advice, and to the many people who carried out tasks such as interviewing, dataentry, and data-processing. It is important that DHS and MICS surveys continue to provide data in future, on FGM and other topics. Studying harms associated with FGM, Obermeyer ${ }^{9}$ argued randomized control trials are impossible for "socially prescribed customs" such as FGM; other barriers to research include ethical concerns, and lack of access to laboratories in areas where FGM is most prevalent. DHS data allows researchers to analyze the consequences of FGM. Evidence in this paper confirms that FGM is harmful; this is consistent with previous literature. ${ }^{6}$ Shell-Duncan ${ }^{2}$ stated that information on FGM by daughters of respondents "is generally regarded as more reliable than women's self-reports since daughter's FGM/C occurred more recently". The FGM module used by DHS (and MICS) surveys since 2010 asks respondents about the circumcision status of each of their daughters; hence, data on daughters are becoming available in more countries. ${ }^{18}$ However, there is a problem with analysing FGM status of daughters: if a respondent reports that their daughter was not circumcised at the time of interview, this might be because her daughter was young at the time of interview; if the daughter was cut after the interview, the apparent prevalence rate is misleading. This is complicated by age differences in FGM practices: some ethnic groups carry out FGM at younger ages than other groups. "Where most cutting is performed by age 5 , as is the case in Senegal, the prevalence in 5-9 and 10-14 cohorts will reflect recent changes in the prevalence of FGM/C. By contrast, in countries such as Egypt and Kenya where many girls are cut after the age of 10, the data in the youngest cohorts are highly censored, and do not provide a clear picture on recent change". ${ }^{23}$ As a result, "In countries where FGC occurs largely at the ages of 10 and above, the current FGC status of girls will be much lower than their final FGC status, and thus daughter data will be less useful for recent program evaluation". ${ }^{18}$ It is desirable to analyse data on FGM among female respondents and their daughters, as is carried out in this paper.

Relatively little FGM research analyses whether harm from FGM depends on age at which FGM was carried out. Larsen et al., ${ }^{22}$ took account of age-when-circumcised, but concluded this was not relevant to whether or not FGM reduced the fertility of women. Slanger et al., ${ }^{24}$ report a study on possible links between occurrence of episiotomy and whether the mother had undergone FGM: this risk was not significantly related to the age at which FGM occurred. Bjälkander et al. ${ }^{21}$ analysed nine forms of 'complications' arising from FGM, in a sample of women from Sierra Leone: shock, bleeding, fever, urine retention, fainting, swelling, tears, wounding, and wound infection. The fraction experiencing 'fever' was lower among girls who underwent FGM when over 10 years old (compared to girls who underwent FGM when aged 10 or younger); all of the other eight types of harm were more common among girls who underwent FGM when over 10 years old (only two of these eight differences were statistically significant, but this may be due to the relatively small sample-size analyzed by Bjälkander et al., $\left.{ }^{21}\right)$. Hence, evidence in Bjälkander et al., ${ }^{21}$ generally supports the pattern in Figures 2 \& Figure 4 of this paper: FGM tends to be more dangerous if the victim is older. But Bjälkander et al., ${ }^{21}$ did not distinguish between different
Types of FGM; they might not be able to detect subtle complications, such as infibulation being different to other Types of FGM - this paper seems more reliable, as an investigation of age-differences in FGM, due to work by people who designed and carried out DHS surveys.

\section{Conclusion}

Social scientists research FGM, using various approaches such as focus groups. The well-being of millions of girls \& women can improve, if research and campaigning continue to persuade politicians \& law-enforcement agencies to oppose FGM. For this task, DHS surveys are a very impressive resource for researchers. FGM is a controversial subject: for example, it could be seen as outsiders from rich western countries seeking to impose 'feminist' values on Africa. Many observers claim FGM is an example of patriarchy. ${ }^{25}$ Some writers avoid the term 'Female Genital Mutilation', choosing to describe the process as 'cutting' or 'circumcision'; but it has been argued that "any definitive and irremediable removal of a healthy organ is mutilation". ${ }^{23}$ This paper cannot resolve such disputes, but is intended to provide more information - which could inform future policies of local, national, and international organizations. Analysis in this paper (based on DHS data) suggests that FGM is usually more harmful if it is carried out on older girls/women, than on younger girls - as shown in Figures $2 \&$ Figure 4. However, FGM Type III (Figure 3) seems to show the opposite pattern: FGM is more risky if carried out on younger children. This paper makes it clear that FGM at any age is likely to harm victims. If people need a ritual to demonstrate their femininity, or their ethnic group, or that they have become an adult, it would be preferable for alternative rituals to be adopted instead of FGM. ${ }^{13}$

\section{Acknowledgments}

None.

\section{Conflict of interest}

None.

\section{References}

1. Rawat R. The association between economic development, education and FGM in six selected African countries. African Journal of Midwifery and Women's Health. 2017;11(3):137-146.

2. Shell-Duncan B, Hernlund Y. Female circumcision in Africa: dimensions of the practices and debates. In: Duncan $\mathrm{S}$, et al. editors. Female circumcision in Africa: culture, controversy, and change, USA: Lynne Rienner; 2000

3. Coyne CJ, Coyne RL. The identity economics of female genital mutilation. Journal of Developing Areas. 2014;48(2):137-152.

4. Ahmadu F. Rites and Wrongs: An Insider/Outsider reflects on power and excision. In: Duncan SB, et al. editors. Female circumcision in Africa: culture, controversy, and change. USA: Lynne Rienner Publishers; 2000. p. 312-328.

5. Yoder PS, Abderrahim N, Zhuzhuni A. Female genital cutting in the demographic and health surveys: a critical and comparative analysis. USA: DHS Comparative Reports number 7; 2004. p. 1-79.

6. Hegazy AA, Al-Rukban MO. Male circumcision: review and authors perspective. The Health. 2012;3(1):24-30.

7. Hegazy A. Female circumcision in Egypt. Annals of International Medical and Dental Research. 2016;2(1):1-2. 
8. Kaplan A, Hechavarría S, Bernal M, et al. Knowledge, attitudes and practices of female genital mutilation/cutting among health care professionals in The Gambia: a multiethnic study. BMC Public Health. 2013;13:851.

9. Obermeyer CM. The consequences of female circumcision for health and sexuality: an update on the evidence. Cult Health Sex. 2005;7(5):443-461.

10. ACORD. Pastoralism in West Africa: marching towards social justice in West Africa; 2008.

11. CELEP. Mobility as a critical condition for economic and social development'. CELEP position paper: Coalition of European Lobbies on Eastern African Pastoralism, West Africa; 2014. p. 1-4.

12. Finke E. Genital Mutilation as an expression of power structures: Ending FGM through education, empowerment of women and removal of taboos. Afr J Reprod Health. 2006;10(2):13-17.

13. UNICEF. Changing a harmful social convention: Female Genital Mutilation/Cutting'. USA: Innocenti Digest; 2005. p. 1-54.

14. Costello S, Quinn M, Tatchell A, et al. A Tradition in Transition: Female genital mutilation/cutting: A literature review, an overview of prevention programs and demographic data for Australia; 2014.

15. National Population Commission (NPC) [Nigeria] and ICF International. 'Nigeria Demographic and Health Survey 2013'. USA; 2014.

16. Simister J. Domestic violence and Female Genital Mutilation in Kenya: effects of ethnicity and education. Journal of Family Violence. 2010;25(3):247-257.
17. Harding M. Ideals and the Hippocratic Oath; 2015.

18. Yoder PS, Wang S. Female Genital Cutting: The interpretation of recent DHS data. DHS Comparative Reports number 33, USA: ICF International; 2013. p. 1-73.

19. DHS. Survey search results: by Female Genital Cutting. Demographic and Health Surveys; 2018

20. DHS. Gender Indicator Data; 2018.

21. Bjälkander O, Bangura L, Leigh B, et al. Health complications of female genital mutilation in Sierra Leone. Int J Womens Health. 2012;4:321-331.

22. Larsen U, Yan S. Does Female Circumcision Affect Infertility and Fertility? A Study of the Central African Republic, Cote D'Ivoire, and Tanzania. Demography. 2000;37(3):313-321.

23. Shell-Duncan B. Considerations on the Use and Interpretation of Survey Data on FGM/C. Addendum to the SOTA. November 2016', Evidence to end FGM/C: research to help women thrive. USA: Population Council; 2016. p. 1-17.

24. Slanger TE, Snow RC, Okonofua FE. The impact of Female Genital Cutting on first delivery in southwest Nigeria. Stud Fam Plann. 2002;33(2):173184.

25. UNICEF. Female Genital Mutilation/Cutting: A statistical overview and exploration of the dynamics of change. USA: United Nations Children's Fund; 2013. 